\title{
A conjuntura após junho de 2013: olhares cruzados sobre participação política e resistência
}

\author{
Antonio Euzébios Filho ${ }^{\text {** }}$ \\ Raquel Souza Lobo Guzzob \\ aUniversidade de São Paulo, Instituto de Psicologia, Departamento de Psicologia Social e do Trabalho. São Paulo, SP, Brasil \\ ${ }^{b}$ Pontifícia Universidade Católica de Campinas. Campinas, SP, Brasil
}

\begin{abstract}
Resumo: Buscamos compreender o que pensam jovens sobre a conjuntura, especialmente no Brasil, após as chamadas manifestações de junho. Em um cenário marcado pela crise social e econômica do capitalismo, quisemos entender como estudantes universitários e de um cursinho popular relacionam-se com o contexto político atual. Foram realizadas entrevistas e o conteúdo foi interpretado com base no materialismo histórico e dialético. Com isto, notamos que os participantes não enxergam um caminho concreto para superação dos problemas identificados nesta conjuntura, a saber: a existência de uma onda conservadora e corrupção, associados à retirada de direitos sociais. Em geral, partidos e movimentos sociais não estão no horizonte de participação, assim como as eleições não foram citadas como um caminho para alcançar demandas populares, corroborando a existência de uma crise de representatividade política, que é reforçada pela falta de alternativa política ao que está posto.
\end{abstract}

Palavras-chave: conjuntura, juventude, consciência, representatividade política.

\section{Introdução}

O momento político no Brasil, certamente, não é de calmaria. Assistimos a um turbilhão de fatos e acontecimentos que ilustram um cenário de instabilidade social e econômica que se acirrou desde as manifestações de junho de 2013. Vivemos um momento de intensificações dos processos de terceirização (contratação de terceiros sem vinculação direta com a empresa) e flexibilização das leis trabalhistas, criminalização dos movimentos sociais, fragmentação da luta sindical, entre outras características que resultam de anos de aprofundamento do neoliberalismo (Antunes, 2008; Boito Júnior, 2003; Marcelino, 2008; Pochmann, 2014). Por outro lado, movimentos sociais e setores da juventude também resistem, esboçam ações e apresentam propostas que são capazes de polarizar a sociedade, contrariando a lógica do capital. Todos estes aspectos, somados, nos fizeram querer entender elementos da consciência política ${ }^{1}$ (Iasi, 2006; Euzébios Filho, 2011) de

* Endereço para correspondência: aeuzebios@hotmail.com

1 Optamos neste trabalho pelo uso do termo "consciência política", mas, sendo coerente com a perspectiva teórica adotada, cabe diferenciar o termo citado daquilo que Marx e Engels (1845/2005) entendem por consciência de classe. Para os filósofos, toda consciência política manifesta-se, menos ou mais, a partir dos vínculos reificados entre classes sociais, isto é, pelas relações que sustentam o sistema financeiro e produtivo. $\mathrm{O}$ entendimento sobre as relações econômicas da sociedade e a negação prática dos fundamentos do liberalismo em diferentes esferas da vida humana elevam o nível de consciência política, se tomamos como referência os parâmetros ético-políticos estabelecidos por Marx e Engels. Mas consciência política no plano da individualidade não é de modo algum sinônimo do que os autores denominaram consciência de classe "para si". Esta é compreendida como possibilidade histórica, possibilidade esta que reúna condições materiais e ideológicas, coletivas e organizativas para a classe pensar e agir como classe. Isto posto, justificamos o uso do termo "consciência política" pelo limite agentes da atual conjuntura, que atuam como protagonistas ou coadjuvantes deste momento histórico.

Este artigo procurou compreender o que pensam jovens (estudantes de um cursinho popular e de uma universidade pública) sobre a conjuntura, especialmente depois das manifestações de junho de 2013. Chegamos a este objetivo pela relevância do nosso contexto político atual, mas também pela importância de a psicologia lançar um olhar sobre a conjuntura e sobre como determinados setores da sociedade vêm interagindo com ela. A psicologia deve se ocupar em entender não apenas os aspectos "privados" da consciência, mas determinadas mediações que se estabelecem entre sujeito e sociedade. Para tanto, é necessário entender a natureza destas mediações, mais especificamente as mediações estabelecidas entre consciência e política. Isto posto, a primeira tarefa que assumimos foi buscar entender o cenário contemporâneo com apoio de autores que discutem a conjuntura na atualidade, a partir do materialismo histórico e dialético (Ali, 2012; Alves, 2012; Antunes, 2008; Frizzo, 2014). Também buscamos entender a realidade atual a partir de estudos sobre o comportamento político e eleitoral de jovens de diferentes camadas sociais (por exemplo, Florentino, 2008; Messenberg, 2015; Telles, 2009) para analisar a leitura que os participantes deste estudo fazem do momento atual, e quais os modos de indignação e resignação possíveis de serem captados nos discursos colhidos neste trabalho.

Depois das chamadas jornadas de junho de 2013, quando milhares de pessoas foram às ruas no Brasil, observamos, inegavelmente, um crescimento de

empírico deste estudo, que trata da manifestação do fenômeno no plano das singularidades. 
insatisfações e revoltas populares no país. Mas o que elas necessariamente significam? E, uma vez se apresentando com frequência nas ruas, como as diferentes pautas se aproximam ou se distanciam?

Claro está que não se pode dar só uma cara para as manifestações que vêm povoando nosso cotidiano desde 2013, transitando entre a esquerda e a direita ${ }^{2}$, nem sempre de forma clara. Como exemplos, podemos citar as mobilizações em favor do impeachment da ex-presidenta Dilma Rousseffe as manifestações contra as reformas trabalhista e da previdência do governo de Michel Temer, também impulsionadas pelos escândalos da Operação Lava Jato. ${ }^{3}$

Em uma primeira mirada podemos constatar que as demandas políticas vêm se apresentando de forma pulverizada até os dias de hoje: a moderação de reivindicações contra a corrupção, por exemplo, vem dando a tônica de um cenário composto por atores que, majoritariamente, questionam timidamente as estruturas do Estado ou simplesmente não questionam a ordem capitalista. De nosso ponto de vista, os pilares de sustentação político-ideológica do capital não estão falindo imediatamente, mas se colocam cada vez mais suscetíveis a alguma forma de contestação. Assim, também passeiam pelas ruas pautas abertamente anticapitalistas desde os

2 O termo "esquerda" será empregado em dois sentidos: de forma ampla, que é aquela que, segundo Cardoso (2016) e Ricci (2009), foi legitimado pelo uso desde a revolução francesa e remete a todos os setores da sociedade que lutam por justiça e igualdade social, dentro e fora do parlamento; e, em um segundo sentido, referimo-nos à esquerda socialista, que, por sua vez, é aquela que engloba o que Tonet (2005) denomina esquerda democrática e revolucionária. As duas falam abertamente em socialismo, mas a diferença é que a primeira propõe chegar lá por meio de reformas graduais, por dentro do Estado, e a segunda propõe a ruptura revolucionária como saída para a tomada do poder dos trabalhadores. É importante salientar que houve uma reconfiguração do conjunto da esquerda após a queda do muro de Berlim, como aponta Kolbrunner (2014) e Cardoso (2016), que se caracteriza pelo enfraquecimento da perspectiva revolucionária e fortalecimento da perspectiva reformista ou simplesmente de pautas específicas (etnia, meio ambiente, por exemplo), que nem sempre se mostram associadas à tomada do poder da classe. Direita, por sua vez, também é um termo legitimado desde a revolução francesa (Cardoso, 2016; Ricci, 2009) e será empregado ao longo do texto a partir da caracterização de Bobbio (1995). Para o autor, a direita prima pela liberdade individual, mesmo que isto implique na desigualdade social. Esta liberdade, sabemos, está ancorada na primazia da propriedade privada e no modo de vida burguês. Mas a direita também tem diferenças - que, para Cardoso (2016), variam do liberalismo econômico ao liberalismo conservador. Porém, é válido reconhecer que elas são táticas, não princípios. Diante da complexidade de definição, não daremos conta de entrar nos detalhes, assim como não teremos tempo de analisar como a direita e a esquerda assumiram diferentes formatos ao longo da história e que também dão vida às chamadas posições de centro.

3 Referimo-nos à operação empreendida pela Polícia Federal denominada Lava Jato, que vem sendo difundida amplamente nos noticiários e vem sendo conhecida por prender ou indiciar figuras tradicionais do cenário político e parlamentar, entre elas a ex-presidenta Dilma (Partido dos Trabalhadores - PT) e o atual presidente, Michel Temer (Movimento Democrático Brasileiro - MDB). Também citamos duas reformas da atual administração do Governo Federal (2017). Basicamente, a reforma trabalhista (Projeto de Lei (PL) nº 6.787/2016) pretende colocar os acordos coletivos acima da legislação trabalhista vigente. Para entender o que ela propõe, ver publicação do Departamento Intersindical de Estatística e Estudos Socioeconômicos (2017b). Por sua vez, a reforma da previdência (Proposta de Emenda Constitucional (PEC) $n^{\circ}$ 287/2016) propõe o aumento de anos de contribuição, entre outros pontos negativos ao trabalhador. Para entender criticamente o que ela propõe, consultar Departamento Intersindical de Estatística e Estudos Socioeconômicos (2017a). movimentos mundiais antiglobalização, que se fortalecem na Europa, especialmente nos setores da juventude (Ali, 2012), passando por partidos e sindicatos, historicamente atrelados ao campo da esquerda, que reivindicam bandeiras ligando-as, explicitamente, ao socialismo.

É imperativo reconhecer que a complexidade da conjuntura atual também corresponde às inúmeras variações de pautas que se apresentam no parlamento e nas ruas, entre bandeiras tradicionalmente identificadas como de direita ou de esquerda ${ }^{4}$, que colocam um cenário caracterizado por um misto de polarização e confusão ideológica (Euzébios Filho, 2011). Ainda assim, tem sido difícil identificar processos que geram unidade programática para qualquer um dos lados.

As movimentações após as manifestações de 2013 também não foram suficientes para superar, até o momento atual, a fragmentação de um amplo campo da esquerda, acirrada no Brasil desde o primeiro mandato de Lula (Antunes, 2008; Frizzo, 2014; Iasi, 2006). Mas em que pese uma onda conservadora (Urban, 2004) - a qual discutiremos ao longo deste trabalho -, entendemos que há possibilidades de resistência ao capitalismo e elas podem ser acentuadas, na atualidade, com o agravamento das crises cíclicas do capital, em um sistema econômico que, como dizia Marx e Engels (1845/2005), gera cada vez mais tensões sociais, desigualdades, intolerância e miséria humana.

$\mathrm{Na}$ busca de elementos para uma análise do momento político atual, tomamos contato com jovens, estudantes universitários e de um cursinho popular, para tentar entender se enxergam (e como enxergam) caminhos de resistência e mudança social. Antes, como já dissemos, tratamos de discutir alguns elementos da conjuntura, tendo como ponto de partida as manifestações de junho de 2013.

\section{As manifestações de junho e as manifestações da consciência política na atualidade}

O neoliberalismo não veio sem resistência popular, pois também foi acompanhado de crises sociais e econômicas. Contudo, vem se caracterizando como um golpe duro nos trabalhadores, à medida que vem retirando direitos sociais (Antunes, 2008), enfraquecendo organismos de classe com as terceirizações e flexibilização das leis trabalhistas (Antunes, 2008; Boito Júnior, 2003; Pochmann, 2014), aumentando a desigualdade social e a distância entre ricos e pobres (Shorrocks, Davies, \& Lluberas, 2014) etc.

4 O Instituto Data Folha fez uma interessante caracterização de pautas tradicionalmente defendidas pela direita e pela esquerda, no período das eleições municipais de 2012. Lá apresentam-se diferenças em relação, por exemplo, à legalização das drogas e do aborto, à intervenção estatal e militar na política e na economia, entre outras diferenças. A esta informação é importante adicionar outra: estudo publicado pelo Data Popular em agosto de 2014 revela que $59 \%$ dos jovens eleitores entrevistados, entre 16 e 33 anos, acreditam que o país seria melhor se não tivesse nenhum partido político (Rodrigues, 2014). Indicador que, em nossa opinião, reforça a tese de que não há um partido, seja de direita ou de esquerda, que aglutine diferentes setores da sociedade em torno de um projeto comum. 
Somado a estes fatores, a sequência de decepções e desesperanças geradas por governos neoliberais tidos como de esquerda, como foi o caso do governo Lula e Dilma no Brasil, vem gerando um questionamento não apenas em relação à possibilidade de mudança estrutural na sociedade, como em torno das estruturas partidárias e sindicais (Florentino, 2008). Neste último caso, este questionamento pode ser observado, especialmente, entre os jovens, como mostra estudo realizado por Florentino (2008). No lugar das estruturas formais do partido, setores da juventude são atraídos por movimentos voláteis, sem uma direção formal, que aparentemente flutuam sobre as demandas da estrutura econômica (Ali, 2012). São aqueles considerados "novos" movimentos sociais (Prado, 2002), que congregam setores em torno de pautas específicas, que, por vezes, assumem táticas autonomistas ou abertamente anarquistas $^{5}$, mas nem sempre acompanhadas de uma perspectiva classista (Ali, 2012).

São estas as características, por exemplo, de movimentos anticapitalistas como aqueles observados na replicação do "Occupy Wall Street" pelo mundo. A origem destes movimentos continua sendo motivada pelas reivindicações históricas da classe trabalhadora, contrárias às estratégias de exploração, taxas de desemprego, precarização das condições de vida e trabalho, mas também pela marginalização dos imigrantes, entre outras reivindicações acumuladas, historicamente, pelos setores oprimidos e explorados (Ali, 2012). O que muda é a identificação das causas, que parece ser a globalização ou os aspectos da opressão de classe - mas elas, paradoxalmente, não se articulam, necessariamente, a um projeto universalista de emancipação da classe trabalhadora (Alves, 2012). Assim, como substituição a um horizonte considerado tão distante (e quem sabe tão perigoso) como o socialismo, vislumbra-se uma vida não globalizada, um capitalismo mais humano, ou uma perspectiva de resistência localizada.

Isto é o que podemos notar, em grande medida, nas manifestações iniciadas em junho de 2013 em todo o Brasil, quando observamos a atuação de grupos anticapitalistas, caracterizados pela propaganda da ação direta contra a polícia e símbolos do capital, como, por exemplo, o Movimento Passe Livre (MPL) e mais diretamente os Black Blocs (Solano, Manso, \& Novaes, 2014).

Inicialmente, as manifestações foram impulsionadas pelo MPL, dando início a uma das maiores mobilizações populares da história do país (Frizzo, 2014). Porém, as manifestações, no desenvolver do processo, trouxeram à tona a diversidade de grupos organizados, além de reivindicações espontâneas, nas mais diversas

5 Aqui é importante diferenciar rapidamente o autonomismo do anarquismo. O primeiro se coloca como um movimento espontâneo, atrelado a pautas específicas, como de negros e negras, feminismo e LGBT. Estão presentes em sua maioria na juventude e não estão atrelados, necessariamente, ao movimento anarquista historicamente constituído. Este, por sua vez, apresenta variações que se ligam mais às estruturas de organização partidária do que, propriamente, diferenças com uma estratégia comunista. Para seguir com esta discussão, consultar Euzébios Filho (2016). combinações possíveis entre o que se convencionou chamar de direita, centro e esquerda.

Diante desta complexidade, seria possível identificar quem vem capitaneando os gritos e as reivindicações das ruas, principalmente, entre uma massa de reivindicações espontâneas? Com este questionamento, Melo (2015) adverte que a direita voltou para as ruas muito por causa de um vazio político deixado pela fragmentação das pautas de esquerda, especialmente da esquerda socialista. Para caracterização da nova direita brasileira, como denomina, o autor cita movimentos como o Movimento Brasil Livre (MBL), que defende, por exemplo, privatizações e endurecimento da repressão às greves e contra a própria esquerda. Neste sentido preciso, podemos afirmar que há uma onda conservadora, e deste modo temos de reconhecer que ela chegou ao seu estágio atual, no Brasil e no mundo, após a queda do muro de Berlim, especificamente, quando se impõe a ideologia do "fim da história" (Fukuyama, 1992), enfatizando a derrocada do chamado socialismo real como elemento de supremacia das teses da democracia liberal.

É preciso lembrar, contudo, que a onda conservadora também vem convivendo com um processo relativamente generalizado de insatisfação em relação ao sistema político-institucional, mais especificamente à democracia representativa, como mostram estudos sobre o comportamento político e eleitoral de jovens brasileiros (por exemplo, Florentino, 2008; Messenberg, 2015; Telles, 2009). A crise de uma democracia institucionalizada ${ }^{6}$ vem do fato de ela não ter atendido às expectativas geradas desde sua implementação no país, ainda mais considerando que, com o neoliberalismo, cada vez menos setores da sociedade vêm sendo incluídos nas políticas sociais.

Deste modo, cresce a desconfiança popular em relação aos caminhos indicados pelos partidos de direita (e por que não, a muitos considerados de esquerda) para solução da perene crise econômica, o que abre espaço para deslegitimar o sistema de representatividade política instituído. A deslegitimação ocorre em vários campos e vai desde os processos de burocratização sindical (Marcelino, 2008), passando por uma descrença em qualquer perspectiva de mudança social (Kollbrunner, 2014), até chegar a uma desconfiança em relação ao próprio sistema democrático, como mostra estudo realizado pelo Instituto Brasileiro de Opinião Pública e Estatística (2015), que indica uma

\footnotetext{
6 Importante destacar que quando mencionamos neste texto "crise da democracia" estamos tratando da crise das instituições que formatam a democracia burguesa. No entanto, a exemplo do que apresentamos sobre as diferentes formas de esquerda e direita (e internamente em cada um desses polos), há várias concepções de democracia, inclusive de democracia burguesa. Por exemplo, Urban (2004) cita o nacionalismo como uma concepção que não questiona o capital e o Estado burguês na sua essência como instrumento de dominação de classe, podendo caminhar para versões fascistas ou extremadas, como o nacionalismo xenofóbico. A crise da democracia burguesa se manifesta também neste sentido, uma vez que o nacionalismo confronta o liberalismo mais atrelado ao capital estrangeiro. Porém, assim como Urban (2004), entendemos que a crise é gerada, especialmente, pela falta de perspectivas de mudança e de melhoria das condições de vida, dada a lógica acumulativa (e de afunilamento social e econômico) do capital privado.
} 
desconfiança nas instituições democráticas entre todas as faixas etárias, inclusive entre os jovens pesquisados. Esta desilusão com o sistema (que não corresponde a uma simples ausência de consciência política, pelo contrário) é sentida, especialmente, pela juventude brasileira (Florentino, 2008). Então, com um sistema partidário regendo a institucionalidade, é natural que os partidos, de forma geral, passassem a ser, em grande medida, identificados como os principais responsáveis por esta democracia inoperante, formal e burocratizada.

Para Iasi (2006), a consciência política não se caracteriza por níveis estáveis de consentimento e contestação do capitalismo. Esta tese é reforçada quando vemos nos dias de hoje uma intensa (e confusa) combinação de elementos conservadores com elementos de ruptura da ordem social. Assim, a dialética da negação e consentimento da ordem (Iasi, 2006) se torna mais clara quando observamos, com frequência, não existir identidade mecânica entre a origem de classe, uma determinação real, e sua consciência acerca dessa determinação.

A consciência parece vagar acima dessas determinações permitindo combinações improváveis, como pequenos burgueses com consciência proletária, proletários com consciência pequeno-burguesa, camponeses mais convictos do projeto proletário que o próprio proletário, capitalistas com convicções socialistas e socialistas com fortes convicções burguesas. $\mathrm{O}$ fato é que a consciência é ela mesma uma das determinações do ser de classe. (Iasi, 2006, p. 337)

Com isso, não podemos concluir que a classe trabalhadora seja ontologicamente reformista ou ontologicamente revolucionária (Iasi, 2006).
Consideramos, ao contrário, que existam diferentes graus de envolvimento político, demarcados, historicamente, pela ação dos sujeitos reais. Esses graus se expressam pelas escolhas, pelas decisões tomadas, pelas formas de se posicionar diante de determinadas dimensões de sua vida no vasto campo da economia e da política.

Os movimentos contraditórios da consciência é que deram o tom dos discursos dos participantes, como veremos a seguir, quando continuaremos a discutir a conjuntura dialogando com os jovens de nossa pesquisa.

\section{Participantes}

Participaram deste estudo 11 estudantes de uma universidade pública do interior do estado de São Paulo e 15 de um cursinho popular localizado na mesma cidade. Trata-se de um cursinho gratuito que atende somente estudantes de escolas públicas e é subsidiado pela referida universidade pública, que, por meio de verbas de extensão universitária, fornece espaço físico e estrutura material e pedagógica para seu funcionamento.

As principais características dos participantes foram divididas em dois blocos de informações: dados de identificação (que engloba idade, sexo e dados socioeconômicos) e dados relacionados à vivência política (participação política e informação sobre a vida política). Notar-se-á que as tabelas 1 e 2 não dividem os dados entre os dois públicos - estudantes universitários e do cursinho popular. A opção por sintetizar as informações deve-se ao fato de nosso foco ser investigar as diferenças e semelhanças entre os participantes de maneira geral, e não necessariamente entre dois públicos, ainda que isto, em certa medida, apareça nos resultados. Vejamos, então, as características gerais dos participantes deste estudo.

Tabela 1. Caracterização inicial dos participantes

\begin{tabular}{|c|c|c|c|c|c|}
\hline Dados & Idade & Sexo & Escolaridade & Renda familiar & Empregabilidade \\
\hline $\begin{array}{l}\text { Total: } \\
\mathrm{n}=26\end{array}$ & $\begin{array}{c}60 \% \text { entre } 18 \text { e } 20 \text { anos } \\
40 \% \text { entre } 20 \text { e } 22\end{array}$ & $\begin{array}{l}65 \% \text { feminino } \\
35 \% \text { masculino }\end{array}$ & $\begin{array}{c}57 \% \text { estudante de cursinho } \\
43 \% \text { universitários } \\
85 \% \text { pretendem ingressar ou ingressaram } \\
\text { no ensino superior por meio das cotas }\end{array}$ & $\begin{array}{l}75 \% \text { de } 1 \text { a } 4 \\
\text { salários-mínimos } \\
25 \% \text { acima de } 5 \\
\text { salários-mínimos }\end{array}$ & $\begin{array}{l}5 \% \text { exerce } \\
\text { atividade } \\
\text { remunerada }\end{array}$ \\
\hline
\end{tabular}

Tabela 2. Informações sobre a vivência política dos participantes

\begin{tabular}{ccc}
\hline Dados & Experiências e envolvimento político & Acesso aos meios de informação \\
\hline & & Internet: $100 \%$ \\
$75 \%$ afirmaram não ter participado & Especificamente redes sociais e blogs: $40 \%$. \\
& Blogs: $8 \%$ (sendo $4 \%$ identificados como \\
déntese. & ou vivenciado nenhuma experiência política & Televisão: $7 \%$ de respostas \\
Total: $\mathrm{n}=26$ & Jornais e revistas: $6 \%$
\end{tabular}


Destes dados é possível reconhecer que se trata de uma população jovem, que, em geral, ainda não ingressou no mundo do trabalho ( $95 \%$ sem atividade remunerada) e não teve intensas vivências no campo da política (apenas $10 \%$ dos entrevistados, todos estudantes universitários, afirmaram participar do movimento estudantil, entidades ou coletivos políticos). Estas características, certamente, interferem no modo de enxergar o mundo e o universo político ao redor, parecendo, estes, serem dimensões ainda muito abstratas aos participantes.

Mesmo com estas e outras possíveis semelhanças, é importante ressaltar que, assim como Florentino (2008), não consideramos a juventude como categoria teórica. Por outro lado, é verdade que este termo se justifica se consideramos uma geração que vive um momento histórico semelhante. Porém, quando nos referimos aos jovens como participantes desta pesquisa, fazemos menção apenas à faixa etária dos participantes, entre $18 \mathrm{e}$ 22 anos. Denominamos simplesmente de Participante (P) 1 a P11 os estudantes universitários e P12 a P26 os estudantes do cursinho.

\section{Procedimentos de coleta das informações}

A pesquisa foi aprovada pelo Comitê de Ética da universidade em que ela foi realizada (número do CAE: 54374616.0.0000.5398). Assim, após escolha aleatória de amostra, realizamos contato com os participantes em sala de aula (separadamente para estudantes universitários e do cursinho), quando foram explicados os objetivos da pesquisa e solicitado que respondessem, por escrito, às perguntas lidas em voz alta e colocadas na lousa. Foi entregue uma folha contendo dados de identificação e duas questões, que guardam relação com os objetivos desta pesquisa: (1) como enxerga o contexto político atual depois das manifestações que correram em 2013?; (2) que caminhos visualiza para os aspectos negativos ou positivos da conjuntura?

\section{Procedimentos de análise}

Não buscamos identificar aspectos de uma consciência individual, ou a soma de opiniões como quer a psicologia tradicional. Como afirma Martins (2006), a consciência também aparece no discurso, mas a linguagem é um fenômeno particularmente social e singularmente genérica, que se desenvolve pela unidade dialética entre subjetividade e objetividade. Assim, também considerando que nosso desafio é lidar com um fenômeno em movimento, estamos cientes que as informações obtidas não são capazes de chegar a uma "verdade" sobre o que pensam os jovens acerca da política na atualidade. Com as informações, trazemos apenas alguns elementos para o debate científico em torno de determinadas manifestações políticas. Isto significa que, por meio dos procedimentos metodológicos adotados, propomos uma análise teórica dentro dos limites do momento empírico.
Os discursos sobre determinados temas foram agrupados, em um primeiro momento, por similaridade de temáticas abordadas. O agrupamento destes discursos em temas permitiu interpretar, teoricamente, as questões particulares do nosso objeto de estudo. Estas interpretações foram possíveis pela identificação de aspectos centrais e secundários dos discursos (Jacques, 1993). A hierarquização do conteúdo não se deu apenas pela repetição das informações, mas pela relevância qualitativa que elas assumiram na construção dos pensamentos apresentados pelos participantes.

Assim, chegamos a três categorias de análise, denominadas de acordo com as interpretações do discurso. São elas: (1) "mais interesse pela política da população e dos jovens após as manifestações de 2013", o que ocorre na avaliação de $65 \%$ dos estudantes do cursinho; (2) "onda conservadora como característica predominante da conjuntura atual", conforme caracteriza grande parte dos universitários; (3) "limites e possibilidades de resistência no contexto atual", quando os participantes discursam sobre estratégias de enfrentamento à onda conservadora ou simplesmente contra a corrupção.

\section{Mais interesse pela política da população e dos jovens após as manifestações de 2013}

Segundo Romão (2013), as manifestações de junho de 2013 foram movidas por uma conjuntura que agregou pelo menos quatro fatores preponderantes: (1) a existência de um movimento organizado, o MPL; (2) a descabida repressão policial que, a certa altura dos acontecimentos, alterou o posicionamento da grande mídia a favor dos manifestantes; (3) a concomitância de um evento esportivo de âmbito mundial; e (4) o contexto de descontentamento generalizado com o sistema político.

Como veremos no transcorrer dos resultados, os participantes indicam em suas análises, de uma forma ou de outra, todos os elementos destacados por Romão (2013). Destacamos apenas um elemento não considerado pelo autor e pelos próprios participantes: em que pese o papel protagonista do MPL e da juventude de forma geral, também é importante lembrar que os sindicatos tradicionalmente alocados no campo da esquerda, embora venham encontrando obstáculos concretos com a flexibilização das leis trabalhistas, criminalização das greves e desestruturação sindical (Antunes, 2008; Boito Júnior, 2003; Marcelino, 2008; Pochmann, 2014), ainda têm um papel relevante na conjuntura atual. Assim, é importante lembrar que, em 2013, no ano das manifestações, o Brasil registrou um número recorde de greves, inclusive no setor industrial (Dieese, 2015).

Fato que houve, a partir de 2013, um elemento novo na conjuntura: mais pessoas estão indo às ruas para manifestar-se politicamente. Isto não passa desapercebido na visão dos participantes: por exemplo, $65 \%$ dos 
estudantes do cursinho popular concordam que uma das características da atualidade se refere ao aumento do interesse de jovens pela política. Como indica P14: "Após as manifestações, a população, em sua grande maioria, discute e participa da política". Ainda para P14, "as manifestações já demonstraram que a população, em grande parte, tem interesse em participar mais ativamente". Alguns universitários também opinam nesta direção: "A população, em sua grande maioria, está mais disposta a discutir e manifestar seus interesses. Estão mais abertos ao diálogo político" (P6). Da mesma forma, P13 afirma: "O Brasil em geral, depois das manifestações de 2013, está mais participante da política, buscando com mais frequência informações sobre a situação atual do país e até mesmo organizando mais manifestações como a desse ano". E P5 coloca: "E o principal é que observamos jovens cada vez mais ligados a assuntos políticos, não ficando passivos a esses assuntos".

Igualmente, P10 considera que há mais envolvimento da sociedade com a conjuntura nacional, mas pondera dizendo que a "mídia" vem atuando como para barrar ou minimizar a participação política. Assim, coloca: "Após as manifestações, notei que as pessoas estão dando maior importância política, apesar da mídia querer mostrar que as situações mudaram para melhor, elas tendem para o meio que o convém, e isso influencia na participação política das pessoas" (P10).

Na mesma direção, P1 associa o aumento na participação política, especialmente de jovens, depois de junho de 2013, e P15 analisa a influência negativa da grande mídia para reforçar o que ele chama de "conceitos arcaicos da política". Cita, porém, que as "massas" vêm adquirindo "maior senso crítico", mas não se aprofunda na questão.

Não podemos concluir o que P15 considera como "senso crítico". Porém, se ele aparece como contraponto aos "conceitos arcaicos" difundidos pela grande mídia, é possível inferir alguma análise acerca desta consideração. Podemos, por exemplo, entender que as redes sociais (meio acessado cotidianamente por quase a metade dos participantes) têm contribuído de alguma forma para dividir a atenção de setores específicos da população sobre política. Evidente que isto não quebra o monopólio dos grandes meios de comunicação, porém, não seria absurdo considerar que, em muitos casos, as redes sociais independentes podem ter grande poder de influência, por exemplo, quando observamos que o desempenho de páginas virtuais como a Mídia Ninja - mídia independente que se coloca explicitamente no campo da esquerda e voltada para juventude - superou o da Revista Veja e dos jornais O Estado de S. Paulo e Folha de S. Paulo na cobertura das manifestações de 2013 na categoria chamada "engajamento no Facebook" ("Mídia Ninja ultrapassa grandes veículos em engajamento no Facebook", 2016).

Por estas e por outras razões, não é de se descartar a tese de que uma parte significativa da população "acordou" (P15), ainda que não tenhamos visto até o momento uma quebra da "ideologia do fim da história" (Kolbrunner, 2014), ainda capaz de retratar um cenário hegemônico em que a sociabilidade capitalista figura como única possibilidade histórica.

\section{Onda conservadora como característica predominante da conjuntura atual}

A percepção de uma onda conservadora revela-se no discurso de alguns estudantes universitários. Em 55\% das respostas analisadas, os universitários entrevistados consideram a polarização e a confusão ideológica como marcas da conjuntura atual. Outras $55 \%$ respostas citam a existência dessa onda conservadora. Para P6, por exemplo: "É possível que haja mudanças sim, entretanto há muitas forças conservadoras em ascensão que podem frear ou até mesmo parar essa mudança na participação política".

$\mathrm{Na}$ mesma direção, P1 avalia que o cenário atual é "marcado por uma conjuntura de cortes e precarizações e intenso retrocesso nas diversas esferas da sociedade". Isto ocorre, segundo P10, pois "as manifestações políticas foram conduzidas a apoiar falsas propostas de mudanças que partiram de grupos políticos conservadores, reacionários e neoliberais. $\mathrm{O}$ contexto é de acirramento político e social, com aumento da repressão e ajustes fiscais".

Desta afirmação, fica claro um elemento importante do processo de luta política nos últimos anos: as reinvindicações de massa ocorridas após 2013 foram apropriadas em certo sentido por setores mais nucleares da burguesia que identificamos como a direita tradicional, mas que autores como Melo (2015) vêm caracterizando como "nova direita, qual seja, a do fundamentalismo econômico com uma agenda neoconservadora, baseada na defesa de costumes tradicionais, oposição ferrenha às chamadas minorias e à agenda ambiental" (p. 9). As mobilizações desta direita têm sido capitaneadas não apenas pelos centros partidários já tradicionalmente identificados com esta agenda no Brasil, mas também por movimentos como Vem Pra Rua e Movimento Brasil Livre. Este impulso da direita brasileira, que retomou a tática de ir para as ruas com apoio da grande mídia (Melo, 2015), de alguma maneira se manifestou nas urnas, especialmente no cenário eleitoral de 2016 e no processo de impeachment.

Para alguns universitários, a onda conservadora vem prevalecendo, como afirma P8: "os conservadores estão levando vantagem, vide o impeachment". Isto significa que a onda conservadora pode ser associada ao impeachment, e que este processo seria mais um indicador de fortalecimento do conservadorismo político. Isto talvez possa parecer claro nos discursos, por exemplo, quando um participante afirma: "Agora em 2016 entendo um movimento crítico de perda de direitos, retrocessos e de favorecimento de certos grupos" (P8). E P4 confirma esta percepção quando diz: "Penso que depois das manifestações de junho o que ocorreu foi bastante diferente das expectativas que foram criadas sobre o que viria a seguir". 
Com as informações disponíveis nesta pesquisa, não pudemos identificar, exatamente, quais pautas estão relacionadas à "onda conservadora". O que foi possível observar é que, na ótica dos participantes, principalmente universitários, as manifestações de junho não resultaram em um processo de conquistas de direitos. Segundo Urban (2004), a onda conservadora desponta, principalmente, em um momento de agravamento das crises cíclicas do capital, como vivemos de maneira mais constante nas décadas que sustentam o neoliberalismo. Neste caso, o conservadorismo se apresenta do ponto de vista econômico, social e político, como observa o autor ao analisar os movimentos e partidos abertamente protofascistas na Europa. Urban afirma, ainda, que o conservadorismo se apresenta na forma de autoritarismo, inclusive militar - na defesa da intervenção militar, por exemplo, mas também em valores associados à pena de morte, caça aos comunistas, xenofobia etc. $\mathrm{O}$ autor também se refere ao contexto latino-americano e lembra o histórico dos processos ditatoriais vividos em diferentes países da América Latina. Neste sentido, Urban (2004) avalia não só que as lutas para derrocada das ditaduras militares burguesas não foram capazes de eliminar os partidos de extrema-direita, como alguns partidos de direita mais moderados saíram fortalecidos deste processo.

No Brasil não foi diferente, assim como, no cenário atual, a justificativa para um maior conservadorismo também vem sendo atribuída à eleição de partidos considerados, pela opinião pública, como sendo de esquerda. Mas, pelo contrário, a falta de respostas sociais dos governos federais do PT - especialmente nos mandatos da Dilma Rousseff, que atravessaram uma conjuntura econômica mais dramática (Singer, 2015) abriu, paradoxalmente, espaço para as manifestações conservadoras na política e na sociedade, que sempre estiveram presentes dentro e fora do Estado, mas que, em alguma medida, tornaram-se mais explícitas, por exemplo, em pautas como redução da maioridade penal, estatuto da família, reforma do ensino médio - considerada por um dos participantes como "absurda" (P4) -, entre outras.

\section{Limites e possibilidades de resistência no contexto atual}

O cenário institucional continua sendo palco de reivindicações populares, mesmo que predominem demandas por mudanças particulares no funcionamento da sociedade. O processo eleitoral, por seu turno, também continua legitimado, em que pese o aparato midiático em torno das eleições no Brasil. Assim, P6 revela: "Vivemos numa democracia e, deste modo, escolhemos nossos representantes. . poderíamos ter maior ciência de que elegemos, mudando assim o nosso atual quadro político".

As eleições, porém, parecem figurar apenas como uma das preocupações dos participantes. A maioria dos universitários entrevistados (85\%) entende que a resistência pode ser levada a cabo fora do contexto institucional. Por exemplo, P6 coloca que, "existindo uma organização popular com objetivos claros, é possível" resistir. Mas qual organização popular seria esta?

Para P7, um caminho seria "trazer debates fundados em fatos reais, apresentando referências através de dados estatísticos, históricos, políticos", colocando o conhecimento e o acesso a informação como principais problemas da desmobilização popular. Por outro lado, também parece apontar para os limites de uma democracia que não faz debates em "fatos reais". Isto parece evidenciar que a insegurança em relação à informação traz, em alguma medida, desconfiança em torno do sistema político. A busca de um lugar seguro, contudo, pode vir a ser a de rejeitar a política (muitas vezes confundida com a ação parlamentar), mas este não parece ser o caso, especialmente entre os universitários.

A desconfiança popular nas instituições democráticas parece contribuir para um distanciamento em relação à institucionalidade política, como observado em determinadas camadas da juventude. Fugindo das lógicas institucionais e partidárias, a "educação" (P10) parece despontar como uma das possibilidades de resistência: "Talvez atuar através da educação, esclarecendo sobre aspectos do que é uma 'visão política de esquerda e de direita', mas acho isso extremamente complicado no contexto atual" (P10).

Não se pode analisar, com isto, o que seria para o participante uma "visão de esquerda e de direita". Fato que a defesa de uma educação crítica aparece novamente no discurso dos universitários, como revela P10, que afirma: "É preciso aumentar espaços de discussão e formação críticas e organizar estrategicamente manifestações cada vez mais intensas contra as propostas políticas do Estado atual". Deste modo, parece que a ausência de um conhecimento "crítico" dos "fatos reais" (P7) aparece como elemento que dificulta a organização popular, necessária ao enfrentamento das "propostas políticas do Estado atual" (P7).

Evidente que o conhecimento crítico é necessário para fazer avançar uma consciência política. Assim, Marx e Engels (1845/2005) entendem em A ideologia alemã a importância de superar o idealismo e conhecer, cientificamente, como funciona o capitalismo, a partir de uma compreensão lógica do processo de desenvolvimento histórico da sociedade de classes. Porém, a consciência, como Marx e Engels (1845/2005) analisam, não se resume ao conhecimento, mesmo o científico. A aplicação do conhecimento na realidade é tarefa fundamental da ciência. Da aplicação do conhecimento científico faz-se uma práxis, que é caracterizada como práxis revolucionária do ponto de vista do horizonte de emancipação humana suscitado por Marx e Engels. ${ }^{7}$

A ausência de um movimento contestatório de massas é sentida, com vigor, em momentos de fragilidade da luta sindical (Marcelino, 2008), flexibilização das leis trabalhistas e reestruturação produtiva (Antunes, 2008), hegemonia

7 Em 1871, quando perguntado sobre os propósitos da associação internacional dos trabalhadores, Marx respondeu: "A emancipação econômica da classe trabalhadora pela conquista do poder político. $\mathrm{O}$ uso desse poder político para fins sociais" (Marx, 1871/2004, p. 32). 
ideológica da burguesia, entre outros fatores, incluindo também uma educação tecnificada e mercantilizada, distante das demandas populares (Frizzo, 2014), que é exatamente o modelo contrário da educação preconizada pelos estudantes universitários citados.

Os processos de identificação política também são elementos importantes para a conjuntura e para os processos de resistência, constituindo aspectos fundamentais da consciência política (Iasi, 2006). A identificação com a classe trabalhadora pode ser observada nos discursos de participantes quando estes se mostram solidários aos ataques sofridos pela classe trabalhadora. Isto é, há um conhecimento sobre quem é o principal alvo da onda conservadora: a classe trabalhadora. Neste caso há um reconhecimento empírico, imediato, da luta de classes. Mesmo assim, não se tem claro o que vem junto com o investimento em educação e acesso a informação, como fica claro no discurso de P8, que coloca: "Vejo um papel importante de discussões, mas entendo que não é suficiente". O que seria, então, suficiente?

O que existe, somente na perspectiva de alguns universitários entrevistados, são "movimentos identitários" contra "uma onda conservadora" (P9). Esta e outras afirmações parecerem estar alinhadas com aquilo que revela Euzébios Filho (2016) ao reconhecer uma crescente adesão entre jovens engajados na política com os movimentos identitários ou coletivos estudantis. $\mathrm{O}$ autor afirma que eles, em geral, primam pelo autonomismo, mas não necessariamente negam um método de organização política. Afirmam-se como de esquerda, mas não necessariamente classistas (Euzébios Filho, 2016).

\section{Considerações finais}

Questões ficaram em aberto. Porém, há elementos para crer que vivemos uma onda conservadora que ao mesmo tempo convive com um engajamento mais nítido de setores da juventude que buscam transformar a sociedade e a política. A soma destes dois elementos retrata aspectos contraditórios das manifestações da consciência política na atualidade, que também são revelados nos discursos dos participantes, principalmente quando: (1) falam de uma onda conservadora, mas não a identificam, necessariamente, com a democracia burguesa; (2) falam em transformação social sem estabelecer uma perspectiva de confronto político com o conservadorismo.

Interessante observar que, por um lado, os universitários dão mais ênfase à onda conservadora, enquanto os estudantes do cursinho popular enfatizam a maior participação da população, em geral, na política. Não temos elementos, porém, para entender o porquê desta diferença de enfoque.

De todo modo, é razoável considerar que a incapacidade de a democracia burguesa dar respostas para sua própria crise - tendo o capital de aplicar medidas cada vez mais devastadoras, da destruição do meio ambiente ao recuo das políticas sociais - vem gerando uma crise de representatividade política, o que fica claro entre os participantes, que parecem não enxergar um caminho concreto para superação dos problemas colocados pela conjuntura na atualidade, a saber: retirada de direitos, corrupção e onda conservadora. Cita-se movimento estudantil, entidades estudantis e coletivos políticos de maneira vaga. Definitivamente, os partidos e movimentos sociais não se apresentam como alternativa à onda conservadora ou a um sistema corrupto (muito menos elegem como alternativa os sindicatos, já que nenhum dos jovens participantes possui experiência imediata como trabalhador), assim como as chamadas instituições democráticas e o voto popular não são citados como alternativas para se alcançar demandas populares. É mais um motivo para crer que há uma crise de representatividade política, e que ela pode significar um questionamento (ou não) em relação ao capitalismo.

\section{The scenario after June 2013: crossed perspectives on political participation and resistance}

Abstract: We investigate young people's views on the political situation, especially in Brazil, after the so-called June protests. In a scenario marked by the social and economic crisis of capitalism, we wanted to understand how students of a working-class university preparatory course related to the current political context. Interviews were carried out and interpreted based on dialectical and historical materialism. We noticed that participants do not see a concrete path to overcoming the problems of the present conjuncture, namely: the existence of a conservative wave and government corruption; both associated to attacks on social rights. Generally speaking, political parties and social movements do not appear on the horizon of participation. Similarly, elections were not seen as a path to achieving popular demands, corroborating the notion of a crisis of political representation, aggravated by the lack of alternatives to the political establishment.

Keywords: conjuncture, youth, consciousness, political representation.

\section{La situation après Juin 2013: Crossed semble sur la participation politique et resistánce}

Résumé: Nous cherchons à comprendre ce qu'ils pensent les jeunes au sujet de la situation actuelle, en particulier au Brésil, après les appels de manifestations Juin. Dans un scénario marqué par la crise sociale et économique du capitalisme, nous 
voulions comprendre comment les étudiants et un cours préparatoire populaire sont liés au contexte politique actuel. Des entrevues ont été menées et le contenu a été interprété sur la base du matérialisme historique et dialectique. Avec cela, nous notons que les participants ne voient pas de façon concrète pour surmonter les problèmes identifiés dans la situation à l'heure actuelle, à savoir l'existence d'une vague conservatrice et la corruption associée à la suppression des droits sociaux. En général, les partis et les mouvements sociaux ne sont pas à l'horizon de la participation, ainsi que les élections ne sont pas cités comme un moyen d'atteindre les revendications populaires, ce qui confirme l'existence d'une crise politique de représentation, qui est renforcé par l'absence d'une véritable alternative politique.

Mots-clés: environnement, de la jeunesse, la sensibilisation, la représentation politique.

\section{La coyuntura después de junio de 2013: miradas cruzadas sobre participación política y Resistencia}

Resumen: Buscamos comprender lo que piensan jóvenes sobre la coyuntura actual, especialmente en Brasil, después de las llamadas manifestaciones de junio. En un escenario marcado por la crisis social y económica del capitalismo, quisimos entender cómo estudiantes universitarios y de un cursillo popular se relacionan con el contexto político actual. Se realizaron entrevistas y el contenido fue interpretado con base en el materialismo histórico y dialéctico. Con esto, notamos que los participantes no ven un camino concreto para superar los problemas identificados en la coyuntura en la actualidad, a saber: la existencia de una onda conservadora y corrupción, asociados a la retirada de derechos sociales. En general, partidos y movimientos sociales no están en el horizonte de participación, así como las elecciones no fueron citadas como un camino para alcanzar demandas populares, corroborando la existencia de una crisis de representatividad política, que se ve reforzada por la falta de una alternativa política concreta.

Palabras clave: coyuntura, juventud, conciencia, representatividad política.

\section{Referências}

Ali, T. (2012). O espírito da época. In D. Harvey, E. Teles, E. Sader, G. Alves, H. S. Carneiro, I. Wallerstein ... V. Safatle, Occupy: movimentos de protesto que tomaram as ruas (pp. 65-72). São Paulo, SP: Boitempo.

Alves, G. (2012). Ocupar Wall Street... e depois? In D. Harvey, E. Teles, E. Sader, G. Alves, H. S. Carneiro, I. Wallerstein ... V. Safatle, Occupy: movimentos de protesto que tomaram as ruas (pp. 31-38). São Paulo, SP: Boitempo.

Antunes, R. (2008). As formas contemporâneas de trabalho e a desconstrução dos direitos sociais. In M. O. Silva e Silva, \& M. C. Yazbek (Orgs.), Politicas públicas de trabalho e renda no Brasil contemporâneo (pp. 41-51). São Paulo, SP: Cortez.

Bobbio, M. (1995). Direita e esquerda: razões e significados de uma distinção política. (M. A. Nogueira, trad., $2^{\mathrm{a}}$ ed.). São Paulo, SP: Editora Unesp.

Boito Júnior, A. (2003). A hegemonia neoliberal do governo Lula. Crítica marxista, (17), 12-36. Recuperado de https://goo.gl/knjUCZ

Cardoso, G. A. B. (2016). A esquerda aceitável: a transição do PT para o reformismo no contexto das eleições de 1994, 1998 e 2002. Global Journal of Human Social Science, 16(2), 19-33. doi: 10.17406/GJHSS

Departamento Intersindical de Estatística e Estudos Socioeconômicos (2015). Balanço das greves em 2013. Estudos e pesquisas, (79). Recuperado de https://goo.gl/ jt7nus
Departamento Intersindical de Estatística e Estudos Socioeconômicos (2017a). PEC 287: a minimização da previdência pública. São Paulo: Dieese. Recuperado de https://goo.gl/9A7PoY

Departamento Intersindical de Estatística e Estudos Socioeconômicos (2017b). Reforma Trabalhista: riscos e perdas impostos pelo PL 6.787/2016 aos trabalhadores e ao movimento sindical. São Paulo: Dieese. Recuperado de https://goo.gl/HBy8ds

Euzébios Filho, A. (2011). Psicologia e desigualdade social: um estudo sobre a consciência politica de beneficiários de programas de transferência de renda. Curitiba, PR: Juruá.

Euzébios Filho, A. (2016). Representação política e movimento estudantil no ensino superior: reflexões sobre uma universidade pública paulista. In C. M. Cardoso (Org.), Universidade, poder e direitos humanos (pp. 77-106). São Paulo, SP: Cultura Acadêmica.

Florentino, R. (2008). Democracia liberal: uma novidade já desbotada entre os jovens. Opinião Pública, 14(1), 205-235. Recuperado de https://goo.gl/Fe5hnr

Frizzo, G. (2014). Educação, processos de consciência e as jornadas de junho. Universidade e Sociedade, 23(53), 6-15. Recuperado de https://goo.gl/G2vyHB

Fukuyama, F. (1992). O fim da História e o último homem. Rio de Janeiro RJ: Rocco.

Iasi, M. L. (2006). As metamorfoses da consciência de classe: entre a negação e o consentimento. São Paulo, SP: Expressão Popular. 
Instituto Brasileiro de Opinião Pública e Estatística (2015). Índice de confiança social. Recuperado de https://goo. g1/UT8Q5A

Instituto Data Folha (2012). Qual é a sua ideologia? Folha de S. Paulo. Recuperado de https://goo.gl/jvMyAb

Jacques, M. G. C. (1993). Um método dialético de análise de conteúdo. Revista Psico, 24(2), 34-52.

Kolbrunner, M. (2014). 25 anos da queda do Muro de Berlim: da onda de revolta contra o stalinismo ao retorno do capitalismo. Recuperado de https://goo.gl/umG2B8

Kosik, K. (1961). Dialética do concreto (5a ed.). São Paulo, SP: Paz e Terra.

Marcelino, P. R. P. (2008). Terceirização e ação sindical: a singularidade da reestruturação do capital no Brasil (Tese de Doutorado). Instituto de Ciências Humanas, Universidade Estadual de Campinas, Campinas, SP.

Martins, L. M. (2006). As aparências enganam: divergências entre o materialismo histórico e dialético e as abordagens qualitativas de pesquisa. In Anais da $29^{a}$ Reunião Anual da Associação Nacional de Pós-Graduação e Pesquisa em Educação. Caxambu, MG: Anped. Disponível em https://goo.gl/Y9KGRh

Marx, K. (2004). Entrevistado por R. Landor. In F. Altman (Org.), A arte da entrevista (pp. 29-35). São Paulo, SP: Boitempo. (Entrevista concedida em 1871).

Marx, K., \& Engels, F. (2005). A ideologia alemã (S. D. Chagas, trad.). São Paulo, SP: Centauro. (Trabalho original publicado em 1845).

Melo, D. B. (2015). A direita ganha as ruas: elementos para um estudo das raízes ideológicas da direita brasileira. In Anais do Colóquio Internacional Marx e o Marxismo 2015: Insurreições, passado e presente. Niterói, RJ: Niep Marx. Recuperado de https://goo.gl/chx3La

Messenberg, D. (2015). O paradoxo da democracia: a participação política dos alunos da Universidade de Brasília. Civitas, 15(1), 1-23. Recuperado de https://goo. $\mathrm{gl} / \mathrm{z} 17 \mathrm{hJv}$
Mídia Ninja ultrapassa grandes veículos em engajamento no Facebook (2016). Portal Imprensa. https://goo.gl/Wgck8n

Pochmann, M. (2014). O mito da grande classe média. São Paulo, SP: Boitempo.

Prado, M. A. M. (2002). Da mobilidade social à constituição da identidade política: reflexões em torno dos aspectos psicossociais das ações coletivas. Psicologia em Revista, 8(11), 59-71. doi: 10.5752/P.1678-9523

Ricci, R. (2009). Identidades de esquerda: o que é ser de esquerda no século XXI? Revista Espaço Acadêmico, 99, 5-12. Recuperado de https://goo.gl/fpaXMz

Rodrigues, A. (2014). O que os jovens pensam sobre a política. Isto é. Recuperado de https://goo.gl/9P6tAy

Romão, W. M. (2013). As manifestações de junho e os desafios à participação institucional. Boletim de Análises Institucionais, (9), 11-20. Recuperado de https://goo.gl/VL6ApM

Shorrocks, A., Davies, J., Lluberas, R. (2014). Global wealth report. Zurich: Credit Suisse Research Institute. Disponível em https://goo.gl/DeZjLX

Singer, A. (2015). Quatro notas sobre as classes sociais nos últimos dez anos do Lulismo. Psicologia USP, 26(1), 7-14. Recuperado de https://goo.gl/8Py23b

Solano, E., Manso, B. P. M., Novaes, W. (2014). Mascarados: a verdadeira história dos adeptos da tática Black Bloc. São Paulo, SP: Geração.

Telles, H. (2009). Jovens eleitores: decifra-me ou te devoro. Debate, 2(11), 22-27. Recuperado de https://goo. $\mathrm{gl} / 8 \mathrm{JmUjm}$

Tonet, I. (2005). Educação e emancipação humana. Ijuí, RS: Unijuí.

Urban, M. (2004). El viejo y la nova derecha radical. Barcelona: Crítica Alternativa. 